ISSN 1808-3765

\title{
FRACIONAMENTO DA FERTIRRIGAÇÃO E SEU EFEITO NA PRODUÇÃO DA ALFACE SOB AMBIENTE PROTEGIDO
}

\author{
Gabriel Greco de Guimarães Cardoso ${ }^{1}$ e Antônio Evaldo Klar ${ }^{2}$ \\ ${ }^{1}$ Doutorado em Irrigação e Drenagem - Unesp-FCA, Av. Parque, 171, gabrielgg@unipam.edu.br \\ ${ }^{2}$ Doutorado em Irrigação e Drenadem, USP-ESALQ, Professor Doutor da Faz. Experimental Lageado - Rua José \\ Barbosa de Barros 1780, klar@fca.unesp.br
}

\section{RESUMO}

Buscando quantificar o efeito do parcelamento da fertirrigação no desenvolvimento da alface, esta pesquisa procurou verificar o número de parcelas de fertirrigação que apresentasse o melhor desempenho no crescimento da cultura. O experimento se deu em blocos casualizados, com três repetições, quatro tratamentos de fertirrigação e três lâminas de irrigação (L1, L2 e L3). Em um dos tratamentos de fertirrigação (F1), toda a adubação necessária se deu no início do plantio; no tratamento F2, a metade da adubação se deu no início do plantio e a outra metade no meio do ciclo da cultura, uma vez planejada a colheita em 40 dias após o plantio; o tratamento F3 foi fracionado: 1/3 da adubação no início do plantio, 1/3 depois de 13 dias e o ultimo terço após 26 dias do plantio; o tratamento F4 seguiu o mesmo raciocínio, fracionando a aplicação em 4 partes, de 10 em 10 dias. Logo, os quatro tratamentos de fertirrigação receberam a mesma dosagem de fertilizantes. Os resultados permitiram concluir que a aplicação F1 resultou no pior desempenho, com massa fresca de 135,06 gramas por planta, enquanto o melhor resultado se deu no tratamento F2, com massa fresca de 161,40 g. Em todas as lâminas, o parcelamento $\mathrm{F} 3$ resultou em sistema radicular mais desenvolvido. $\mathrm{O}$ tratamento L1 apresentou em média maior desenvolvimento das raízes, seguido do L2 e L3. O tratamento L1 apresentou menor condutividade elétrica no extrato da solução dos vasos, sendo o único tratamento que diferiu estatisticamente dos demais;

Palavras-chave: Parcelamento da adubação; lâmina de irrigação, produção de massa fresca da alface.

\section{CARDOSO, G. G. G.; KLAR, A. E. FERTIGATION ON LETTUCE PRODUCTION IN GREENHOUSE}

\section{ABSTRACT}

Four fertilizer treatment were applied by irrigation in lettuce crop pots: F1 - all fertilizer at planting; F2 - divided in two parts: half at planting and half 20 days after; F3 - divided in three parts: $1 / 3$ at planting, $1 / 3$ after 13 days and $1 / 3$ after 26 days; and F4 - fractioned every 10 days in four parts. The results showed that F1 presented the worst value (135.06 g per fresh matter plant) and the best was F2 (161.40 g fresh matter per plant). The three irrigation depths, based on minimum soil water potential: L1 (-0.02 MPa), L2 (-0.03 MPa) and L3 ($0.1 \mathrm{MPa})$, showed the evapotranspiration averages: $183.33 ; 169.00$ and $105.08 \mathrm{~g}$ per pot 
respectively. There were all distributed in randomized block design with three replications. Irrigation treatments showed that the lowest frequency water application presented the lowest dry root production. The soil electric conductivity after harvest showed that the most frequent irrigation depth produced lower values in relation to the other depths.

Keywords: parcel fertilization; irrigation depth, lettuce production..

\section{INTRODUÇÃO}

Uma das alternativas para o melhor aproveitamento do sistema de irrigação é a técnica da fertirrigação. Segundo Vivancos (1993), entende-se por fertirrigação a aplicação dos elementos nutritivos necessários aos cultivos juntamente com a água de irrigação.

Costa et al. (1986) citaram que a fertirrigação apresenta como vantagens, a economia de mãode-obra e maquinaria, aplicação no momento exato em que a planta necessita, possibilidade de aplicação em qualquer fase do ciclo da cultura, fácil fracionamento e controle da quantidade de fertilizante aplicada, distribuição mais uniforme, maior eficiência de utilização dos nutrientes e menor dano físico ao solo e à cultura. A fertirrigação permite manter a disponibilidade de água e nutrientes próxima dos valores considerados ótimos ao crescimento e à produtividade da cultura, justamente por permitir controlar as dosagens de forma precisa através dos injetores de fertilizantes. Sendo assim, a quantidade de nutrientes, parcelada ou não, deve ajustar-se às necessidades da cultura ao longo das fases de desenvolvimento.

Frizzone et al. (1985) observaram que a aplicação convencional de fertilizantes é relativamente demorada e, em alguns casos, provoca a compactação do solo. A fertirrigação é bastante rápida e a solução de fertilizante dilui-se de forma homogênea na água de irrigação, distribuindo-se na área juntamente com a água.

Burt et al. (1995) afirmam que a fertirrigação é o mais econômico e eficiente método de aplicação de fertilizantes, especialmente quando aplicado através de sistema de irrigação localizado, desde que esta aplicação assegure os fertilizantes diretamente na região das raízes das plantas, e com o fracionamento das doses, possibilita aumentar a eficiência da adubação. Esses mesmos autores, afirmam que, comparando a fertirrigação por gotejamento e a aplicação de fertilizantes com o método convencional, há um aumento na eficiência de aplicação de fertilizante no primeiro método e gasta 20 a $50 \%$ menos fertilizantes do que o método convencional. Threadgill (1985) relatou que a aplicação de fertilizantes associada com outros insumos agrícolas (herbicidas, inseticidas, entre outros), chega a reduzir os custos em comparação com o sistema convencional em torno de $33 \%$.

Segundo Malavolta (1981), para a fertirrigação nitrogenada, têm sido utilizadas várias fontes comerciais de nitrogênio, obtidas a partir nitrogênio do ar, como uréia, sulfato de amônio, nitrato de amônio, etc. A uréia representa uma das fontes mais econômicas de nitrogênio, sendo completamente assimilável pelas plantas, nas formas amoniacal e nítrica.

As perdas de nitrogênio para a atmosfera se dão na forma de amônia e ocorrem com alta freqüência quando o adubo é aplicado na superfície do solo sem incorporação. Umidade, temperatura, $\mathrm{pH}$, complexo de troca e teor de matéria orgânica, dentre outros fatores, influenciam a perda de nitrogênio para a atmosfera, (Malavolta, 1981). Rodrigues \& Kiehl (1986), avaliando formas de aplicação de uréia em laboratório e em casa de vegetação, com aplicação na superfície do solo, concluíram que a aplicação na superfície resultou na volatilização de quase todo o nitrogênio. Melhor controle foi verificado quando se incorporou o fertilizante a uma profundidade maior. Malavolta (1980) descreveu a conveniência do 
parcelamento do nitrogênio em função da baixa exigência inicial da cultura. As culturas anuais devem receber, no plantio, apenas uma fração da dose de nitrogênio de que necessitam, aplicando-se o restante sobre o solo, ao lado da planta, no período de sua maior exigência. A uréia, quando utilizada como fonte de nitrogênio, deve ser incorporada visando evitar perdas por volatilização, as quais podem atingir 25 a $60 \%$ do total aplicado. Meirelles et al. (1980), trabalhando com adubação nitrogenada em feijoeiro em Terra Roxa Estruturada e usando o sulfato de amônio como fonte de nitrogênio, com a aplicação de $100 \mathrm{~kg} \mathrm{ha}^{-1}$, obtiveram um aproveitamento de $30 \mathrm{~kg} \mathrm{ha}^{-1}$ de nitrogênio e concluíram que a adubação nitrogenada deve ser parcelada, aplicando-se 1/3 da dose no plantio e 2/3 aos 30 ou 45 dias após a germinação.

No intuito de preencher uma lacuna ainda pouco explorada pelos pesquisadores, esta pesquisa buscou estudar os efeitos do fracionamento da fertirrigação sobre um cultivo da alface.

\section{MATERIAL E MÉTODOS}

O experimento foi desenvolvido em uma das casas de vegetação situada na área experimental do Departamento de Engenharia Rural da Universidade Estadual Paulista (Unesp), Campus Botucatu - SP, no período compreendido entre 01 de agosto a 09 de setembro de 2008. A altitude média é $786 \mathrm{~m}$, a latitude é $22^{\circ} 51^{\prime} 03$ ” Sul e a longitude 48 25'37' Oeste. De acordo com a classificação de Köeppen, a região apresenta clima Cfa, ou seja, clima temperado chuvoso, caracterizado pela existência de quatro ou seis meses consecutivos com temperatura média do ar superior a $10^{\circ} \mathrm{C}$. A temperatura média do ar no mês mais quente é de $22,8^{\circ} \mathrm{C}$ e do mês mais frio de $16,7^{\circ} \mathrm{C}$. A média da temperatura do ar anual é de $20,6{ }^{\circ} \mathrm{C}$ e as médias das temperaturas do ar máxima e mínima são de 23,5 e 17,4 ${ }^{\circ} \mathrm{C}$ respectivamente $\mathrm{O}$ total de precipitação pluvial média é de $1518,8 \mathrm{~mm}$, apresentando um total médio para o mês mais chuvoso de $229,5 \mathrm{~mm}$ e 37,5 para o mês menos chuvoso. A evapotranspiração média anual é de $692 \mathrm{~mm}$.

O experimento foi conduzido em uma estufa tipo túnel alto, com dimensões de $15 \mathrm{~m}$ de comprimento, 7,5 $\mathrm{m}$ de largura e altura no centro e nas laterais de 3,0 e $1,7 \mathrm{~m}$ respectivamente. A estrutura tem a forma de arcos de tubos galvanizados. A cobertura é feita com filme de polietileno aditivado, transparente, com $150 \mu \mathrm{m}$ de espessura. As laterais são de tela "sombrite" com 30\% de sombreamento, objetivando a interceptação de insetos e animais. A estufa é posicionada no sentido Norte/Sul, ficando perpendicular à trajetória do sol. No interior da estufa, foi construído um tabuleiro de madeira, com altura de $1 \mathrm{~m}$ em relação ao solo e largura de $70 \mathrm{~cm}$, que tem a utilidade de acomodar os vasos sobre eles. A massa do solo colocada nos vasos, bem como das plantas no momento da colheita, foram medidas por uma balança digital, de menor divisão igual a 5 g. Utilizaram-se vasos plásticos pretos para o plantio da alface, de volume igual a $10 \mathrm{~L}$, aos quais foram cheios com $8 \mathrm{Kg}$ de solo seca ao ar.

O solo foi passado por uma peneira de malha igual a $4 \mathrm{~mm}$, espalhado sobre uma lona no interior da casa de vegetação para secagem, chegando à umidade média de $1,0 \%$ no momento em que foi colocado no vaso. As características físicas e químicas, foram determinadas em amostras deformadas, segundo metodologia de Leite Júnior (2000) e Antunes (2001) no Departamento de Recursos Naturais, da FCA/UNESP e encontram-se dispostos nas Tabelas 1, 2 e 3 . 
Tabela 1. Resultado da análise química do solo:

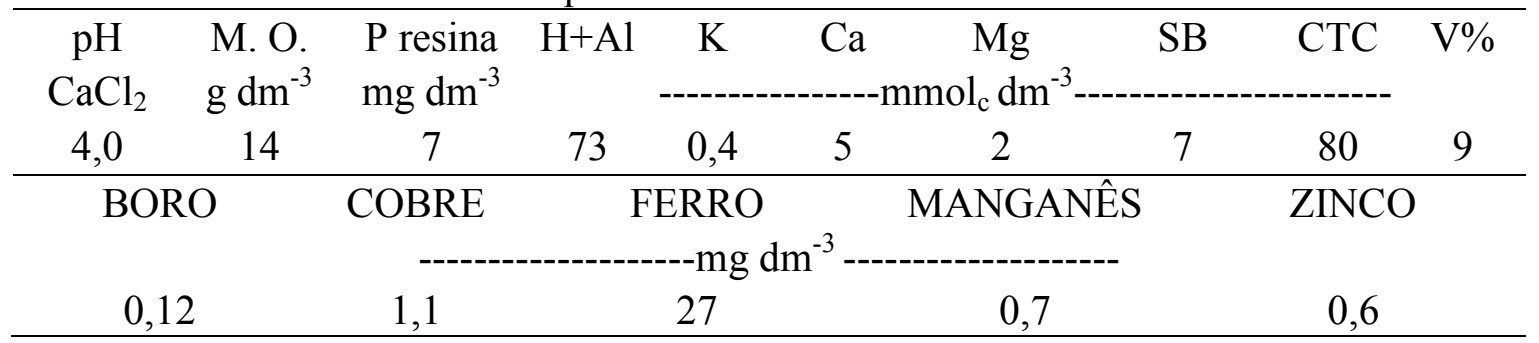

Tabela 2. Resultado da análise granulométrica do solo:

\begin{tabular}{ccc}
\hline AREIA & ARGILA & SILTE \\
\hline \multicolumn{3}{c}{$\mathrm{g} \mathrm{Kg}^{-}$} \\
620 & 318 & 62 \\
\hline
\end{tabular}

Tabela 3. Valores dos teores de água no solo $\left(\mathrm{g} \mathrm{g}^{-1}\right)$ e potencial matricial $(\mathrm{MPa})$

\begin{tabular}{cc}
\hline$\Psi(\mathrm{MPa})$ & $\mathrm{a} \%(\mathrm{~g} \mathrm{~g}-1)$ \\
\hline Saturado & 0,5000 \\
0,003 & 0,3000 \\
0,006 & 0,2400 \\
0,01 & 0,1600 \\
0,03 & 0,1400 \\
0,1 & 0,1200 \\
0,5 & 0,1100 \\
1,5 & 0,1000 \\
\hline
\end{tabular}

O solo foi preparado inicialmente com a calagem e posteriormente, ao longo do ciclo da cultura, adubado via água de irrigação, conforme recomendações do boletim 100 do IAC (RAIJ et al., 1997), para a cultura da alface, com as seguintes quantidades de nutrientes por vaso: $0,3 \mathrm{~g}$ de uréia; $1 \mathrm{~g}$ de $\mathrm{KCl}$ e 8,75 g de $\mathrm{P}$. Em um dos tratamentos de fertirrigação (F1), toda a adubação necessária para o vaso, se deu no início do plantio; no tratamento F2, a metade da adubação se deu no início do plantio e a outra metade no meio do ciclo da cultura, uma vez planejada a colheita em 40 dias após o plantio; o tratamento F3 foi fracionado $1 / 3$ da adubação no início do plantio, $1 / 3$ depois de 13 dias e o ultimo terço após 26 dias do plantio; o tratamento F4 foi fracionando em 4 partes, de 10 em 10 dias. Conseqüentemente, no final do ciclo da cultura, os quatro tratamentos de fertirrigação receberam a mesma dosagem de fertilizantes. A aplicação se deu de forma manual, dissolvendo a quantidade de adubo por vaso em uma garrafa pet com $1800 \mathrm{~g}$ de água e aplicando esta massa de solução ao longo do ciclo da cultura, em conformidade com o tratamento.

Desta forma, todos os vasos iniciaram com a massa líquida total de $10100 \mathrm{~g}$, irrigação incluída. Estabeleceram-se valores mínimos de massa para cada tratamento aos quais os vasos deveriam atingir para serem novamente irrigados. Assim, para cada um dos três tratamentos de lamina de irrigação. As porcentagens mínimas de água no solo para os tratamentos são 12,$00 ; 14,00$ e $15,00 \%$, correspondentes aos seguintes potenciais de água no solo, de acordo com a curva de retenção de água no solo, $-0,1 ;-0,03$ e $-0,02 \mathrm{MPa}$ respectivamente. A irrigação se deu manualmente, por meio de um regador acoplado a uma mangueira flexível. Todos os vasos eram pesados diariamente e quando atingissem a massa estabelecida, eram 
irrigados até que atingissem novamente o valor de 10100 g. A precisão na pesagem foi cuidadosamente observada, com variações de até $5 \mathrm{~g}$, que é a precisão da balança.

No interior da estufa, foi instalado um Tanque Classe A para monitorar a evaporação local, cujas medições foram registradas diariamente, sempre as 9:00 horas (Fig. 1). As temperaturas internas foram registradas por um termômetro de máxima e mínima (Fig. 2).

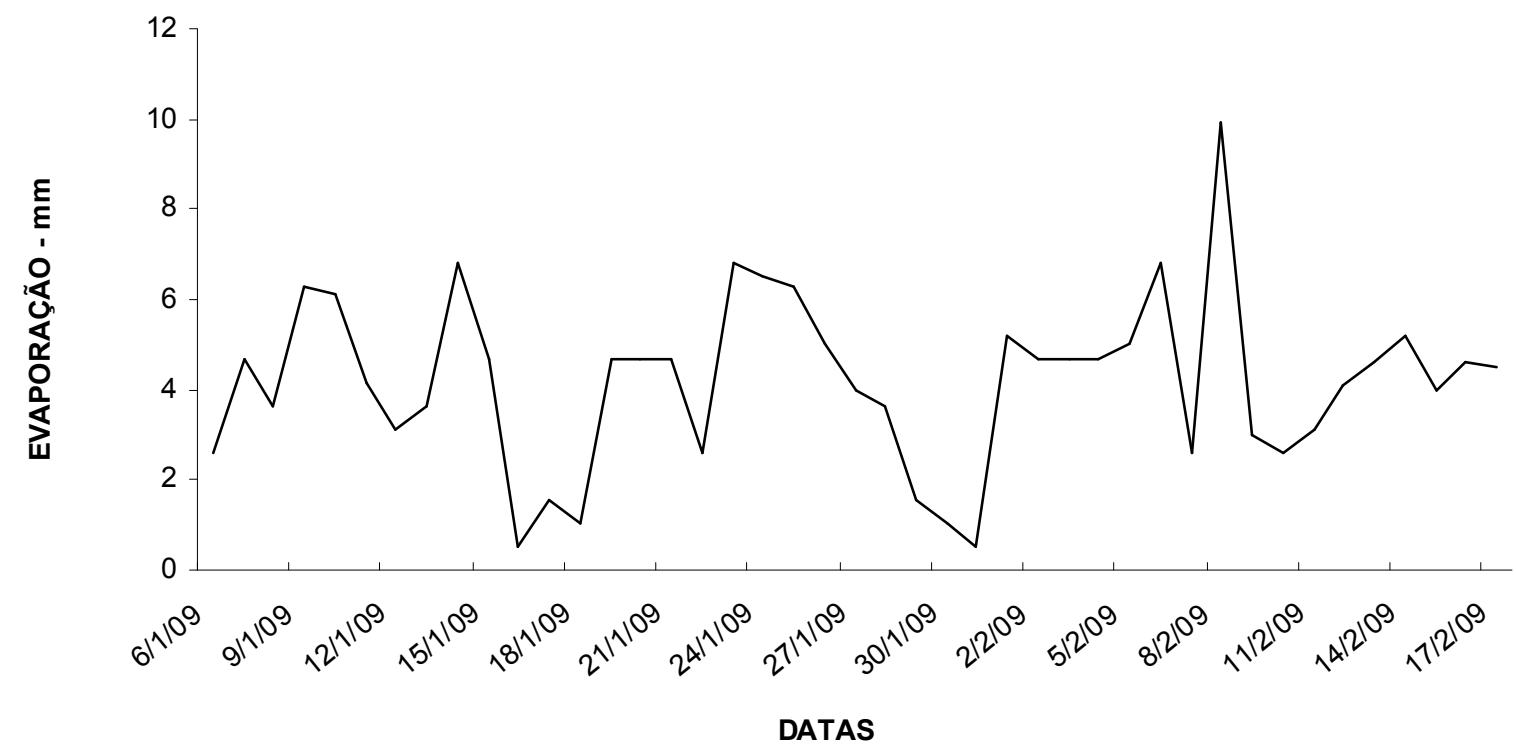

Figura 1. Evaporação registrado pelo Tanque Classe A no período de 06/01 a 17/02/2009.

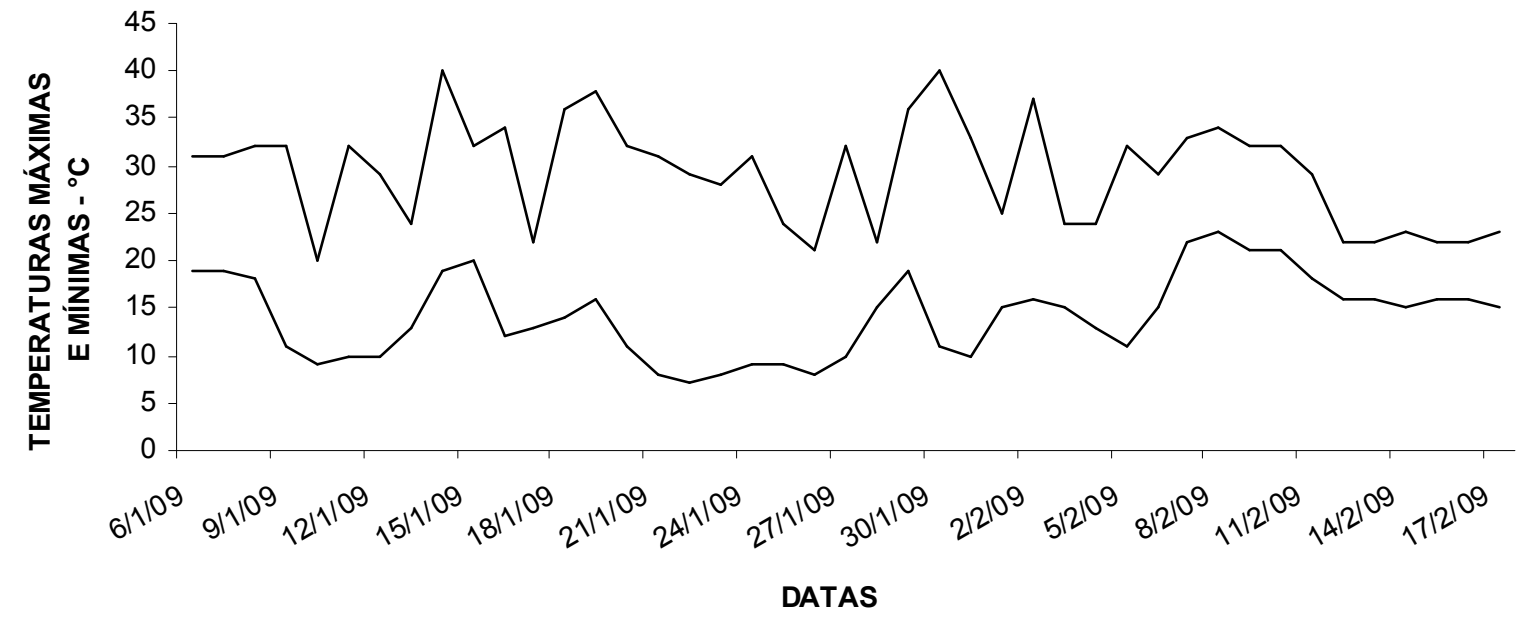

Figura 2. Temperaturas máximas e mínimas no período de 06/01 a 17/02/2009.

Foi determinada a evapotranspiração máxima da alface através dos vasos do tratamento -0,02 $\mathrm{MPa}$, por ter recebido lâminas com maiores freqüências, permanecendo nas condições potenciais durante o experimento.

Após completar 39 dias do plantio, todos os vasos foram pesados e irrigados, para que no dia posterior, as plantas fossem colhidas. $\mathrm{O}$ valor obtido corresponde à massa fresca foi correlacionado com a lâmina aplicada e com os tratamentos de fertirrigação. 
O experimento foi conduzido segundo delineamento em blocos casualizados, contando com quatro tratamentos de fertirrigação, três lâminas de água e três repetições. Para análise estatística, utilizou-se o teste de Tukey, a 5\% de probabilidade.

\section{RESULTADOS E DISCUSSÃO}

Na Tabela 4, observa-se a massa final dos vasos antes das irrigações, os potenciais de água no solo, os respectivos teores de umidade em cada tratamento e os valores das lâminas totais aplicadas para cada tratamento ao longo do experimento, o número de irrigações totais, o turno de rega médio. Para a lâmina aplicada, foi considerada a média geral, não diferenciando os tratamentos de fertirrigação. Observa-se que o tratamento de menor potencial de água foi irrigado menor número de vezes, já que maior foi o tempo para que a água nele contido evapotranspirasse até a massa estabelecida. Já o de maior potencial recebia água com maiores freqüências. Os potenciais de água no solo foram estabelecidos segundo a curva de retenção de água no solo. O turno de rega foi calculado considerando 40 dias de experimento e o número de irrigações ao longo dele.

Tabela 4. Massa mínima dos vasos antes da irrigação; potenciais de água mínimos; teores mínimos de água; lâminas totais de água durante o experimento; número de irrigações e turno de rega média.

\begin{tabular}{ccccccc}
\hline Tratamento & $\begin{array}{c}\text { Massa final } \\
\text { dos vasos } \\
(\mathrm{g})\end{array}$ & $\begin{array}{c}\text { Potenciais } \\
(-\mathrm{MPa})\end{array}$ & $\begin{array}{c}\text { Teores de } \\
\text { Umidade } \\
(\%)\end{array}$ & $\begin{array}{c}\text { Lâmina } \\
\text { Aplicada } \\
(\mathrm{mm})\end{array}$ & $\begin{array}{c}\mathrm{N}^{\mathrm{o}} \text { de } \\
\text { irrigações }\end{array}$ & $\begin{array}{c}\mathrm{TR} \\
\text { Dias }\end{array}$ \\
\hline L1 & 9100 & 0,02 & 15,00 & 114,09 & 6 & 7 \\
L2 & 9000 & 0,03 & 14,00 & 99,55 & 5 & 8 \\
L3 & 8900 & 0,1 & 12,00 & 77,80 & 4 & 10 \\
\hline
\end{tabular}

A Figura 3 mostra a evapotranspiração da alface ao longo do experimento no tratamento de lâmina L1, considerando os tratamentos de fertirrigação. O experimento teve início no dia 06/01/2009, data esta em que os vasos foram irrigados até a massa total de $10100 \mathrm{~g}$, permanecendo nesta condição por 10 dias. Observa-se que, em média, os tratamentos tiveram uma tendência uniforme entre si quanto à evapotranspiração, apesar de que o tratamento F1 iniciou evapotranspirando mais e terminou evapotranspirando menos. Como este tratamento recebeu toda a adubação no início do plantio, teve maior crescimento que os demais. Observam-se também pelo gráfico, o número, as médias e as datas das irrigações. 


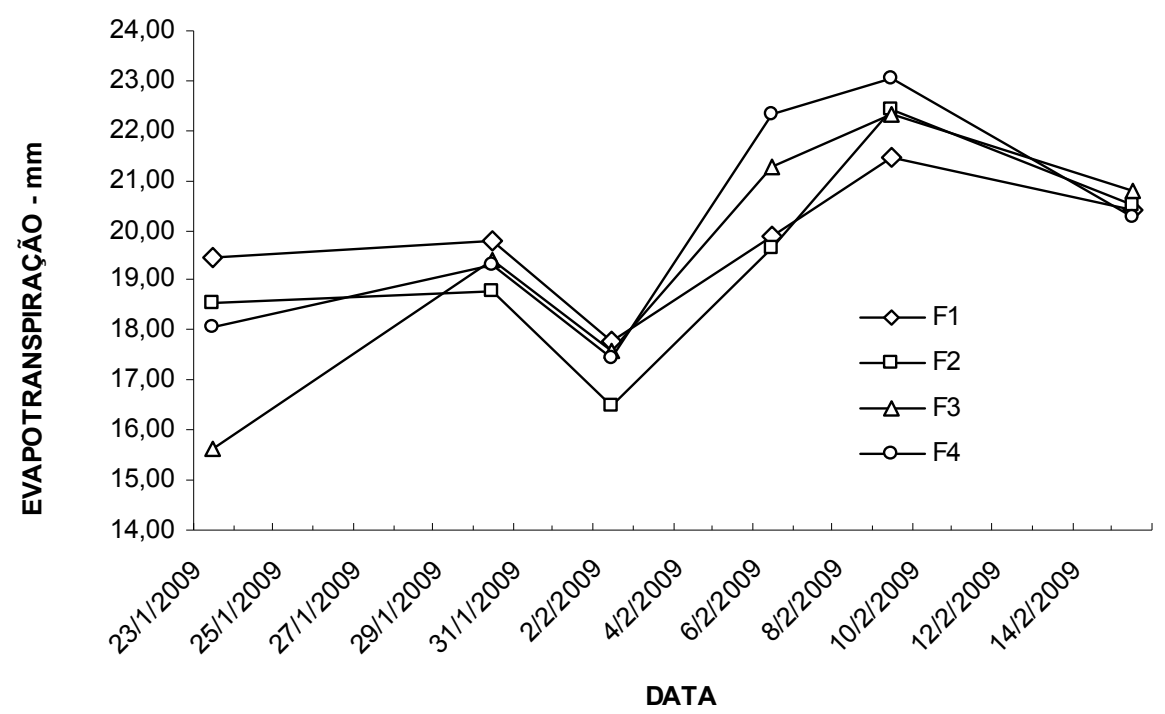

Figura 3. Evapotranspiração das quatro cultivares em função do tempo no tratamento L1.

A Figura 4 ilustra a evapotranspiração registrada no experimento em função dos potenciais de água no solo, para os quatro tratamentos de fertirrigação. $\mathrm{O}$ tratamento de potencial $-0,02 \mathrm{MPa}$ foi o que mais evapotranspirou e também foi o tratamento mais produtivo em massa fresca. Os tratamentos de fertirrigação F4, F2 e F1 foram os que mais evapotranspiraram nos respectivos potenciais de -0,02, -0,03 e -0,1 MPa.

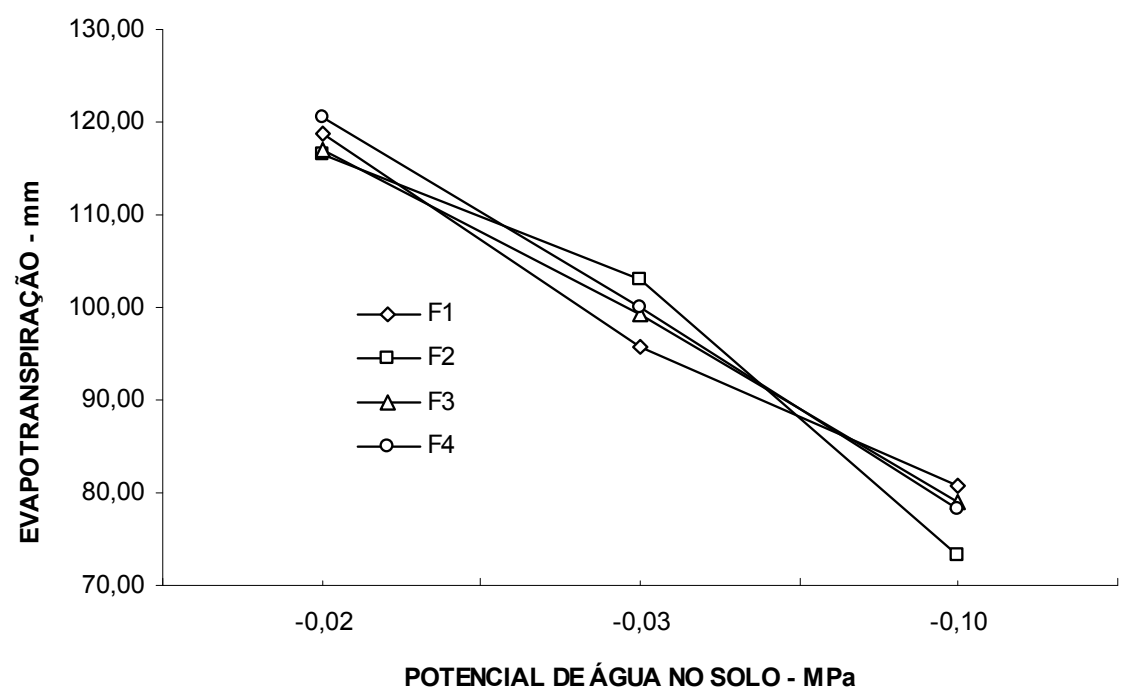

Figura 4. Evapotranspiração em função dos potenciais de água no solo.

A Figura 5 mostra a seqüência da produção de massa fresca em função dos tratamentos de fertirrigação para as três lâminas aplicadas. A lâmina L1 permanece mais produtiva em todos os parcelamentos da fertirrigação. A seqüência de produção para as lâminas L1, L2 e média são iguais, com o tratamento F2 sendo mais produtivo, seguido do F4, F3 e F1, sugerindo que fracionamentos maiores que dois não trazem melhores resultados na produção da alface. É possível que a partir da segunda metade do ciclo da cultura, o nível de atividade fotossintética e metabólica da cultura sofra uma redução, fazendo com que o nível de energia gasta na absorção de nutrientes se reduza também. Assim, fracionamento da fertirrigação que vá além da segunda metade do ciclo da alface não contribui para melhores rendimentos na produção, ao contrario do que é sugerido por Meirelles et al. (1980). Como a 
pesquisa se deu em vasos, onde os nutrientes adicionados ficam contidos no solo, há possibilidade que o mesmo resultado não seja encontrado em plantio sobre o solo natural, pois a percolação de nutrientes seria bem mais intensa, favorecendo um manejo de fertirrigação diferenciado do que é proposto neste trabalho. A lâmina L3 destoa do comportamento das demais lâminas, onde a maior produção se deu no tratamento F3, seguido do F4, F1 e F2. É possível que devido ao estresse causado pela seca, a cultura tenha sofrido alterações em sua fisiologia.

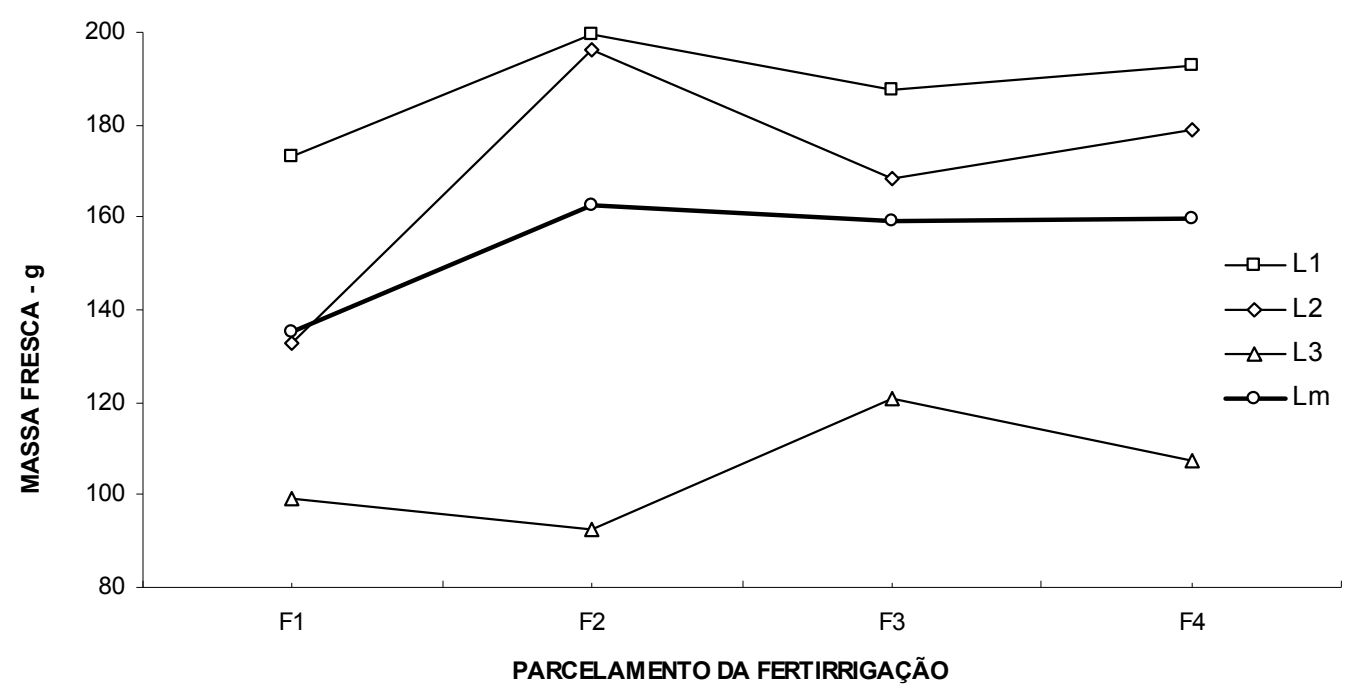

Figura 5. Produção de massa fresca em função dos tratamentos de fertirrigação e lâminas.

A Tabela 5 mostra a média das produções de matérias fresca e a análise estatística usando o teste de Tukey. São observadas diferenças significativas quanto às lâminas e quanto às fertirrigações. Apenas o tratamento $\mathrm{F} 1$ difere dos demais tratamentos de fertirrigação, não havendo, portanto, necessidades de fracionamento da fertirrigação maior que dois, se bem que os dados sugerem que prejuízos não ocorrerão com fracionamentos maiores. Quanto aos tratamentos de lâminas, observa-se diferença significativa entre os três níveis de irrigação, sugerindo que a melhor lâmina de irrigação entre as três, seja a L1.

Tabela 5. Analise estatística da produção de massa fresca $(\mathrm{g})$ considerando os tratamentos de lâmina e de fertirrigação.

\begin{tabular}{cccccc}
\hline Lâminas & \multicolumn{3}{c}{ Tratamentos de Fertirrigação } & Média das \\
\cline { 2 - 5 } Aplicadas & $\mathrm{F} 1$ & $\mathrm{~F} 2$ & $\mathrm{~F} 3$ & $\mathrm{~F} 4$ & Lâminas \\
\hline L1 & $173,3 \mathrm{Aa}$ & $199,6 \mathrm{Ba}$ & $187,6 \mathrm{ABa}$ & $192,6 \mathrm{ABa}$ & $188,27 \mathrm{a}$ \\
L2 & $132,6 \mathrm{Ab}$ & $196,0 \mathrm{Ba}$ & $168,3 \mathrm{Cb}$ & $179,0 \mathrm{BCa}$ & $169,00 \mathrm{~b}$ \\
L3 & $99,3 \mathrm{Ac}$ & $92,6 \mathrm{Ab}$ & $121,0 \mathrm{Bc}$ & $107,3 \mathrm{ABb}$ & $105,08 \mathrm{c}$ \\
\hline Média das & & & & & \\
fertirrigações & $135,11 \mathrm{~A}$ & $161,44 \mathrm{~B}$ & $159,00 \mathrm{~B}$ & $159,66 \mathrm{~B}$ & \\
\hline
\end{tabular}

Média da produção - $153,80 \mathrm{~g}$

Coeficiente de variação - 10,68 \%

Diferença mínima significativa entre as lâminas - 16,74

Diferença mínima significativa entre as fertirrigações - 21,35

Médias seguidas por letras distintas na mesma coluna, diferem entre si a 5\% de probabilidade pelo teste de Tukey. 
A Figura 6 mostra a condutividade elétrica da solução extraída do solo dos vasos após a colheita das alfaces, na unidade de $\mathrm{u} \mathrm{S} / \mathrm{cm}$. Observa-se que para os quatro parcelamentos da fertirrigação, F1, F2, F3 e F4 a mesma tendência de condutividade em função das lâminas são observados, sendo L2 o maior valor, seguido do L3 e L1. Pode-se concluir com esta observação que o tratamento que recebeu maior lâmina, L1, consumiu mais nutrientes da adubação, resultando numa solução de menor condutividade elétrica. Esse consumo de nutrientes possivelmente foi maior devido ao porte mais desenvolvido das plantas, como é observado na Tabela 5. O tratamento L3, em todos os parcelamentos de fertirrigação, absorveu mais nutrientes que o tratamento L2, possivelmente devido ao estresse que a cultura sofreu pela pouca lâmina de irrigação, adaptando-se a absorver mais nutrientes para se manter viva. O parcelamento F3 consumiu mais nutriente, para todas as lâminas aplicadas. Quando se examina a produção de massa fresca deste tratamento, observa-se que ele não é o mais produtivo, e sim o F2, concluindo que a capacidade de absorção de nutrientes não está ligada somente à produção de massa fresca aérea, mas também ao desenvolvimento do sistema radicular, como se observa na Figura 7. Em média, o parcelamento F4 resultou em maiores valores de condutividade, seguidos do F1, F2 e F3. É possível que o tratamento F4 não tenha seguido a tendência de decrescimento da condutividade observado nos demais tratamentos, pelo fato de que a ultima parcela de fertirrigação deste tratamento foi pouco utilizado pela cultura, que já esta se encontrava num estágio de maturação completo.

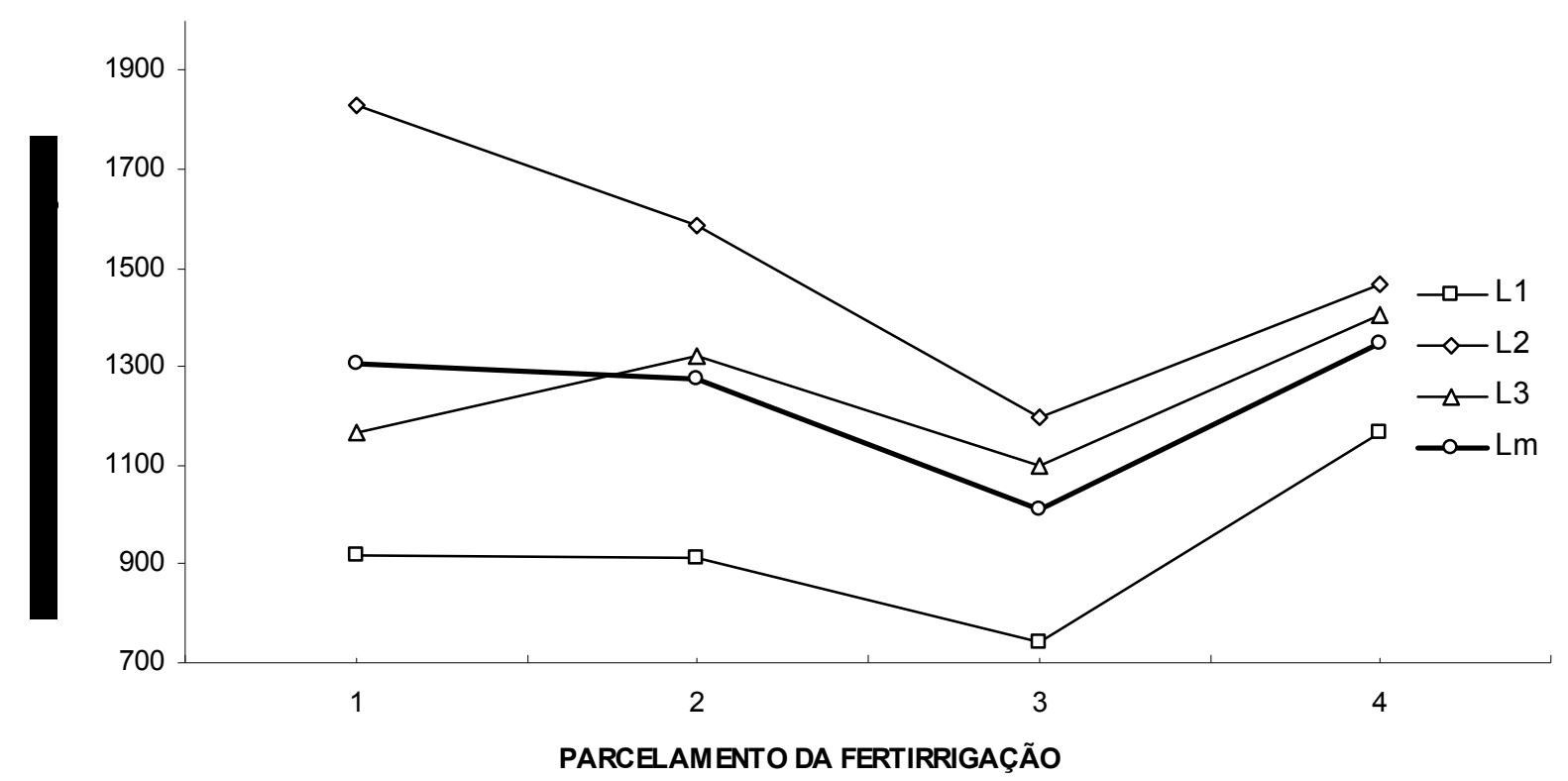

Figura 6. Condutividade elétrica da solução extraída dos vasos em função dos tratamentos de fertirrigação e lâminas.

A Tabela 6 mostra a média das condutividades elétrica da solução extraída dos solos dos vasos em uূS/cma e a análise estatística usando o teste de Tukey. São observadas diferenças significativas apenas nas lâminas aplicadas. Isto sugere que o volume de água aplicado no solo é um fator significativo para favorecer a cultura na absorção dos nutrientes. O tratamento L1 apresentou menor condutividade elétrica, sendo o único tratamento que diferiu estatisticamente dos demais. Não houve diferença significativa entre os tratamentos de 
fertirrigação, sugerindo que o fracionamento da fertirrigação não é um fator que contribui significativamente na absorção de nutrientes pela cultura.

Tabela 6. Analise estatística da condutividade elétrica da solução extraída do solo dos vasos (ųS/cma) considerando os tratamentos de lâmina e de fertirrigação.

\begin{tabular}{cccccc}
\hline Lâminas & \multicolumn{4}{c}{ Tratamentos de Fertirrigação } & Média das \\
\cline { 2 - 5 } Aplicadas & F1 & F2 & F3 & F4 & Lâminas \\
\hline L1 & 919,7 & 913,7 & 742,4 & 1167 & $935,7 \mathrm{~b}$ \\
L2 & 1829 & 1588 & 1195 & 1467 & $1519,7 \mathrm{a}$ \\
L3 & 1168 & 1320 & 1101 & 1405 & $1248,5 \mathrm{a}$ \\
\hline Média das & & & & \\
fertirrigações & $1305,6 \mathrm{a}$ & $1273,9 \mathrm{a}$ & $1012,8 \mathrm{a}$ & $1346,3 \mathrm{a}$ & \\
\hline
\end{tabular}

Média da condutividade - 1234,65 ųS/cma

Coeficiente de variação - 12,94 \%

Diferença mínima significativa entre as lâminas - 346,75

Diferença mínima significativa entre as fertirrigações $-452,06$

Médias seguidas por letras distintas na mesma coluna, diferem entre si a $5 \%$ de probabilidade pelo teste de Tukey.

A Figura 7 mostra a produção de massa seca das raízes em função dos tratamentos de fertirrigação e lâmina. Em todas as lâminas, o parcelamento F3 resultou em sistema radicular mais desenvolvido. Essa tendência já era esperada, já que a Figura 6 mostra que o parcelamento $\mathrm{F} 3$ absorveu mais nutrientes que os demais, mesmo não sendo o parcelamento mais produtivo, como mostra a Figura 5, concluindo que boa parte dos nutrientes absorvidos foram usados no sistema radicular. Houve uma tendência de crescimento das raízes de F1 a F3, vindo a diminuir com no F4. Como foi observado na Figura 6, esse parcelamento não absorveu todo nutriente da última fertirrigação, talvez por causa de sua fase de maturação, deixando de desenvolver a parte aérea e as raízes.

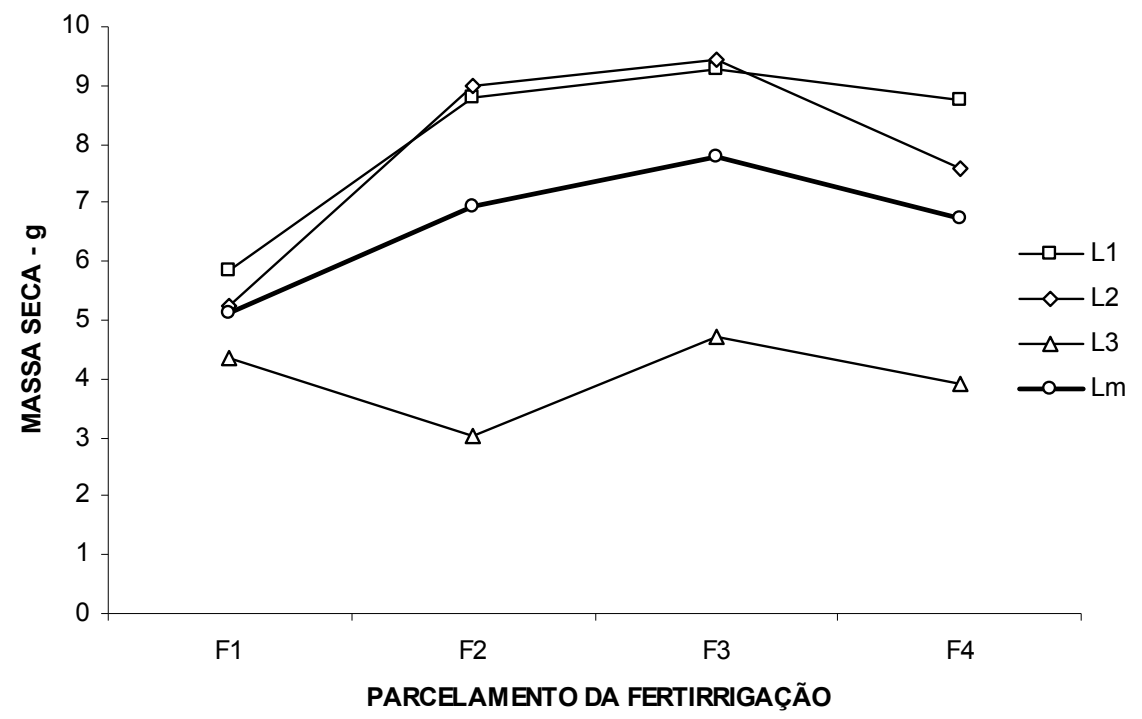

Figura 7. Massa seca das raízes em função dos tratamentos de fertirrigação e lâminas.

A Tabela 7 mostra a média das massas secas das raízes e a análise estatística usando o teste de Tukey. São observadas diferenças significativas apenas nas lâminas aplicadas. Isto 
sugere que o volume de água aplicado no solo é um fator significativo para o desenvolvimento radicular. O tratamento L1 apresentou em média maior desenvolvimento das raízes, seguido do L2 e L3. O tratamento L3 foi o único que diferiu estatisticamente dos demais. Não houve diferença significativa entre os tratamentos de fertirrigação, sugerindo que o fracionamento da fertirrigação não é um fator que contribui significativamente no desenvolvimento das raízes.

Tabela 7. Analise estatística da massa seca das raízes, considerando os tratamentos de lâmina e de fertirrigação.

\begin{tabular}{cccccc}
\hline \multirow{2}{*}{$\begin{array}{c}\text { Lâminas } \\
\text { Aplicadas }\end{array}$} & F1 & F2 & F3 & F4 & Média das \\
\cline { 2 - 5 } Lâminas \\
\hline L1 & 15,7777 & 18,7164 & 18,7164 & 18,6532 & $18,08097 \mathrm{a}$ \\
L2 & 15,1444 & 18,9056 & 19,3415 & 17,4906 & $17,72053 \mathrm{a}$ \\
L3 & 14,253 & 12,9613 & 14,6178 & 13,8266 & 13,91467 \\
& & & & & b \\
\hline
\end{tabular}

\begin{tabular}{l} 
Média das \\
fertirrigações $\quad 15,05837$ a $\quad 16,86110$ a $\quad 17,71197$ a $\quad 16,65680$ a \\
\hline Média da massa $-16,57206 \mathrm{~g}$ \\
Coeficiente de variação - 7,15651 \% \\
Diferença mínima significativa entre as lâminas - 2,57358 \\
Diferença mínima significativa entre as fertirrigações - 3,35516 \\
Médias seguidas por letras distintas na mesma coluna, diferem entre si a 5\% de probabilidade \\
pelo teste de Tukey.
\end{tabular}

\section{CONCLUSÃO}

As alfaces do tratamento L1 foram as que mais evapotranspiraram, bem como foi o tratamento mais produtivo;

$\mathrm{O}$ fracionamento da fertirrigação em duas parcelas apresentou melhor resultado na produção de massa fresca, não havendo diferença significativa na produção para parcelamentos maiores;

São observadas diferenças significativas apenas nas lâminas aplicadas, sugerindo que o volume de água aplicado no solo é um fator imprescindível para favorecer a cultura na absorção dos nutrientes dispostos no solo;

O tratamento L1 apresentou menor condutividade elétrica no extrato da solução dos vasos, sendo o único tratamento que diferiu estatisticamente dos demais;

Em todas as lâminas, o parcelamento $\mathrm{F} 3$ resultou em sistema radicular mais desenvolvido. $\mathrm{O}$ tratamento L1 apresentou em média maior desenvolvimento das raízes, seguido do L2 e L3.

É sugerido maior aprofundamento em estudos deste gênero no intuito de se verificar as conclusões deste trabalho, principalmente usando outras culturas;

\section{REFERÊNCIA BIBLIOGRÁFICA}

BURT, C. O.; CONNOR, K.; RUEHR, T. Fertigation. San Luis Obispo: Califórnia Polytechnic State University, 1995. 295p. 
COSTA, E. F.; FRANÇA, G. E.; ALVES, V. M. Aplicação de fertilizantes via água de irrigação. Informe Agropecuário, Belo Horizonte, v. 12, n. 39, p. 63-8, 1986.

FRIZZONE, J. A.; ZANINI, J. R.; PAES, L. A. D.; NASCIMENTO, V. M. Fertirrigação mineral. Ilha Solteira, UNESP, 1985. 52 p. (Boletim técnico, 2).

LEITE JÚNIOR, J. B. Dessalinização do solo provocada pelo excesso do íon potásssio em latossolo vermelho amarelo cultivado com alface americana (Lactuca sativa L.) irrigada sob ambiente protegido. 2000. 80 f. Dissertação (Mestrado em Agronomia/Irrigação e Drenagem) - Faculdade de Ciências Agronômicas, Universidade Estadual Paulista, Botucatu, 2000 .

MALAVOLTA, E. Elementos de nutrição mineral de plantas. São Paulo: Ceres, 1980. 252 p.

MALAVOLTA, E. Manual de química agrícola: Adubos e adubação. 3. ed. São Paulo: Ceres, $1981.607 \mathrm{p}$.

MEIRELLES, N. M.; LIBARDI, P. L.; REICHARDT, K. Absorção e lixiviação de nitrogênio em uma cultura de feijão (Phaseolus vulgaris, L). Revista Brasileira de Ciência do Solo, Campinas, v. 4, p. 83-8, 1980.

RAIJ, B.; CANTARELLA, H.; QUAGGIO, J.A.; FURLANI, A.M.C. (Ed.) Recomendações de adubação e calagem para o Estado de São Paulo. 2.ed. Boletim Técnico IAC, Campinas, n. 100 , p. 285-314, 1997.

RODRIGUES, M. B.; KIEL, J. L. Volatilização da amônia após uréia em diferentes doses de aplicação. Revista Brasileira de Ciência do Solo, Campinas, v. 10, n. 1, p. 37, 1986.

THREADGILL, E. D. Chemigation via sprinkler irrigation: curreents status and future development. Applied Engineering in Agriculture, v. 1,n. 1, p. 16-23, 1985.

VIVANCOS, A. D. Fertirrigacion. Madrid: Mundi-Prensa, 1993. 217 p. 